\title{
A little more on the appearance of doctors
}

\section{UM POUCO MAIS SOBRE A APARÊNCIA DOS MÉDICOS}

\author{
Ana Beatriz Hortense ${ }^{1}$, José Baddini-Martinez ${ }^{2}$
}

Second-year resident physician, Division of Pneumology, Department of Internal Medicine, Ribeirão Preto Medical School, University of São Paulo, São Paulo, SP, Brazil. ${ }^{2}$ Associate Professor, Division of Pneumology, Department of Internal Medicine, Ribeirão Preto Medical School, University of São Paulo, São Paulo, SP, Brazil.

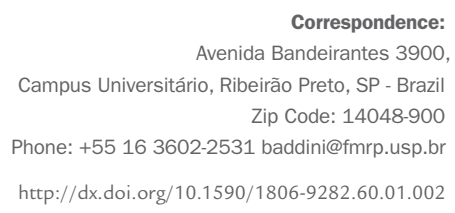

Following the disclosure of the results of the study "Impressions of patients, doctors and medical students regarding the appearance of doctors ${ }^{1}$," some colleagues have called our attention to the increasingly common use of tattoos among medical students, a factor not investigated in that article. Being such skin decoration permanent, we decided to complement the information provided by the previous study with a small research among patients treated at Hospital das Clínicas, FMRP-USP. Sixty patients - 20 inpatients and 40 outpatients, 34 female, mean age $55.6 \pm 15.4$ years - were addressed by the same investigator at all times.

A standard questionnaire was used to detect the presence or absence of discomfort regarding seven personal appearance items used by doctors. Due to the results of the original study, four items were included in each list, in addition to the tattoo element, which had been linked to high level of discomfort, and two with minimum degree of discomfort.

The percentage of patients who would feel uncomfortable with the items studied was:

- for male physicians: Bermuda shorts, $65 \%$; shorts, 65\%; facial piercing, $56.7 \%$; tattoo, $46.7 \%$; many rings,

- $43.3 \%$; closed shoes, $0 \%$; white coat, $0 \%$.

- for female physicians: facial piercings, $58.3 \%$; crop tops, $56.7 \%$; shorts, $50 \%$; tattoo, $43.3 \%$; Bermuda shorts, $41.7 \%$; closed shoes, $0 \%$; white coat, $0 \%$.
The data suggest that between 40 and $50 \%$ of patients would feel uncomfortable if treated by a medical professional with tattoos. Even though these figures are high, other items of appearance, such as facial piercing and use of shorts, had a higher degree of disapproval. Therefore, we can conclude that the degree of disapproval by patients to the use of tattoos by medical doctors is intermediate, suggesting that contemporary society is more accepting of the use of this ornament.

Anyway, these results confirm, once again, the preference of most patients for medical professionals who adopt a more traditional and conservative posture and appearance. ${ }^{1.2,3}$

\section{References}

1. Yonekura CL, Certain L, Karen SKK, Alcântara GAS, Ribeiro LG, BaddiniMartinez J et al Impressões de pacientes, médicos e estudantes de Medicina quanto a aparência dos médicos. Rev Assoc Med Bras 2013. http://dx.doi. org/10,1016/j.ramb.2013.04,005

2. Brandt LJ. On the value of an old dress code in the new millennium. Arch Intern Med 2003; 163:1277-81.

3. Lill MM, Wilkinson TJ. Judging a book by its cover: descriptive survey of patients' preferences for doctors' appearance and mode of address. BMJ 2005; 331:1524-7. 